\title{
PD-1 and PD-L1 Expression in Male Breast Cancer in Comparison with Female Breast Cancer
}

\author{
Quirine F. Manson $^{1} \cdot$ Natalie D. ter Hoeve ${ }^{1} \cdot$ Horst Buerger $^{2} \cdot$ Cathy B. Moelans $^{1} \cdot$ Paul J. van Diest $^{1}$ (I)
}

Published online: 5 December 2018

(C) The Author(s) 2018

\begin{abstract}
Background Male breast cancer is rare, as it represents less than $1 \%$ of all breast cancer cases. In addition, male breast cancer appears to have a different biology than female breast cancer. Programmed death-1 (PD-1) and its ligand, programmed death-ligand 1 (PD-L1), seem to have prognostic and predictive values in a variety of cancers, including female breast cancer. However, the role of PD-1 and PD-L1 expression in male breast cancer has not yet been studied.

Objectives To compare PD-1 and PD-L1 expression in male breast cancer to female breast cancer and to evaluate prognostic values in both groups.

Patients and Methods Tissue microarrays from formalin-fixed paraffin-embedded resection material of 247 female and 164 male breast cancer patients were stained for PD-1 and PD-L1 by immunohistochemistry.

Results PD-1 expression on tumor-infiltrating lymphocytes was significantly less frequent in male than in female cancers (48.9 vs. $65.3 \%, p=0.002)$. In contrast, PD-L1 expression on tumor and immune cells did not differ between the two groups. In male breast cancer, PD-1 and tumor PD-L1 were associated with grade 3 tumors. In female breast cancer, PD-1 and PD-L1 were associated with comparably worse clinicopathological variables. In a survival analysis, no prognostic value was observed for PD-1 and PD-L1 in either male and female breast cancer. In a subgroup analysis, female patients with grade 3/tumor PD-L1-negative or ER-negative/immune PD-L1-negative tumors had worse overall survival.

Conclusions PD-1 seems to be less often expressed in male breast cancer compared to female breast cancer. Although PD-1 and PD-L1 are not definite indicators for good or bad responses, male breast cancer patients may therefore respond differently to checkpoint immunotherapy with PD-1 inhibitors than female patients.
\end{abstract}

Paul J. van Diest

p.j.vandiest@umcutrecht.nl

1 Department of Pathology, University Medical Center Utrecht, PO Box 85500, 3508 GA Utrecht, The Netherlands

2 Institute of Pathology Paderborn/Höxter, Cooperative Breast Center, Paderborn, Germany

\section{Key Points}

PD-1 expression on tumor infiltrating lymphocytes was less often positive in male breast cancers compared to female breast cancers.

Although PD-1 and PD-L1 are not definite indicators for good or bad responses, male breast cancer patients may respond differently to checkpoint immunotherapy with PD-1 inhibitors than female patients.

Female breast cancer patients with grade 3/tumor PD-L1 negative or ER negative/immune PD-L1 negative tumors seem to have worse overall survival. 


\section{Introduction}

Male breast cancer is rare and represents less than $1 \%$ of all breast cancer cases. Consequently, less is known about men with breast cancer compared to women with breast cancer. Generally, male breast cancer has a more advanced stage, a lower tumor grade, and is more often estrogen/progesterone receptor (ER/PR)-positive compared to female breast cancer [1-5]. Due to conflicting data in the literature, it is unclear if men with breast cancer have a different survival outcome than women [6]. As a result of this limited knowledge of male breast cancer, treatment options for this cancer type are mainly based on treatment strategies for postmenopausal women with breast cancer $[1,6]$.

Currently, programmed death-1 (PD-1) and its ligand, programmed death-ligand 1 (PD-L1), are raising much interest for cancer treatment. PD-1 is an immune checkpoint that blocks T cell function by binding PD-L1. Upregulation of PD-1 on tumor-infiltrating lymphocytes (TILs) or expression of PD-L1 on tumor cells have been observed in breast cancer [7-13] and in a variety of other cancer types, including lung [14], melanoma [15], kidney [16, 17], bladder [18], and ovarian cancer [19]. Prognostic and/or predictive values have been suggested in breast cancer, although these results are variable [7-13]. Furthermore, the levels of expression of PD-1 and PD-L1 seem to vary between molecular subtypes, with higher expression of PD-L1 in triple-negative breast cancer (TNBC) compared to non-TNBC [20, 21]. Trials for immunotherapy with checkpoint inhibitors have therefore mostly been focused on TNBC, which have shown promising results [22].

Since male breast cancer seems to have a different biology than female breast cancer, PD-1 and PD-L1 expression may also vary. Considering that male breast cancer is predominantly of the ER-positive luminal type [4], PD-1 and PD-L1 may be less frequently expressed in breast cancer in men, with possibly different prognostic values and response to treatment with checkpoint inhibitors.

Since there are no published studies on PD-1 and PD-L1 expression in male breast cancer, we evaluated the expression of PD-1 and PD-L1 in tumors of men with breast cancer, compared expression frequency to female breast cancer, and evaluated prognostic values.

\section{Materials and Methods}

\subsection{Patients and Samples}

We retrospectively collected tissue blocks and clinicopathological data of 256 consecutive female breast cancer patients who were operated on between 1991 and 2007. In addition, 176 tissue blocks of male breast cancer patients undergoing surgery between 1986 and 2010 were also collected. The female cohort was unselected for familial genetic predisposition ("sporadic") and derived from the Department of Pathology, University Medical Center Utrecht (UMCU), The Netherlands. The male breast cancer tissue blocks were gathered from different pathology laboratories throughout The Netherlands and Germany as described before [2-4]. Anonymized clinicopathological data [age, tumor size, histology, grade (according to the modified Bloom and Richardson score [23]), lymph node status, and surrogate molecular subtype based on hormone receptor status (ER/PR status was assessed according to the Dutch guidelines with a cut-off of $10 \%$ and HER2 was scored according to the ASCO/CAP guidelines)] for both groups were extracted from digital reports or revised by a pathologist specialized in breast cancer (P.v.D.). Anonymized follow-up data were obtained through the Comprehensive Cancer Center of The Netherlands. According to Dutch legislation, which uses an "opt-out" system, the use of leftover material requires no ethical approval or informed consent if used anonymized for scientific purposes [24]. Additionally, the Institutional Review Boards of the UMCU and the University of Muenster, Germany, approved this study.

\subsection{Tissue Microarray and Immunohistochemistry}

Tissue microarrays (TMAs) had already been prepared for previous studies $[4,25]$, by taking three cores of $0.6 \mathrm{~mm}$ from formalin-fixed paraffin-embedded (FFPE) tissue blocks. Of these blocks, 4- $\mu \mathrm{m}$ tissue sections were cut and then immunohistochemically stained for PD-1 and PD-L1 with the Ventana autostainer (Roche, Tuscon, AZ, USA), according to the instructions of the manufacturer. For PD-1, we used the mouse anti-PD-1 monoclonal antibody (ab52587/ NAT105, dilution 1:50; Abcam, Cambridge, UK) and for PD-L1, a rabbit anti-PD-L1 monoclonal antibody [741-4905 (clone sp263, dilution Ventana ready to use; Ventana Medical Systems, Tuscon, AZ, USA)]. ER (Ventana 1:100), PR (Dako 1:100), and HER2 (Neomarkers 1:100) were also stained with the Ventana autostainer.

\subsection{Assessment of PD-1 and PD-L1}

Scoring of the immunohistochemically stained slides was performed by consensus of two experienced observers (P.v.D. and Q.M.), in random order and blinded to other data. PD-1 was considered positive in cases of any membranous staining of TILs, while all other cases were considered as negative. For PD-L1, positivity on both tumor cells and immune cells was scored individually. To score PD-L1 on tumor cells, the percentage of positive membranous staining was estimated. PD-L1 on immune cells was considered as positive in case of any membranous staining of immune cells (lymphocytes or macrophages). To verify representativeness of the TMAs, we compared the tumor PD-L1 TMA 
scores of ten patients to scores on whole slides. For half of the tumors, we observed complete agreement. The other half of the tumors showed only minimal differences.

\subsection{Statistics}

Statistical analyses were performed with IBM Statistics 25 . Differences in clinicopathological variables between male and female breast cancer were calculated using the independent samples $t$-test, Pearson Chi-square test, and Fisher's exact test. To compare PD-1 and PD-L1 expression between both groups, the Pearson Chi-square test was performed. For survival analysis, Kaplan-Meier curves were plotted and compared with the log-rank test. Cox regression was used for multivariate analysis. Significance level was set at $p<0.05$.

\section{Results}

\subsection{Patient Characteristics}

PD-1 and/or PD-L1 scores were obtained from 165 male breast cancer and 246 female breast cancer patients. Baseline clinicopathologic characteristics are shown in Table 1. Compared to women, men with breast cancer were significantly older (66 vs. 58 years), had smaller tumors ( 2.3 vs. $2.6 \mathrm{~cm}$ ), and presented more often with ductal cancers ( 97.6 vs. $91.4 \%$ ) with a luminal surrogate intrinsic molecular subtype (94.5 vs. $82.1 \%)$.

\subsection{PD-1 and PD-L1 Expression}

Expression of PD-1 on lymphocytes, scored as positive or negative (Fig. 1), was significantly different between male and female breast cancer, with less PD-1 positivity on TILs in tumors of men with breast cancer ( 48.9 vs. $65.3 \%, p=0.002$ ).

Concerning PD-L1 staining (Fig. 2), no significant differences were observed in the percentage of PD-L1-positive tumors between male and female breast cancers (using a $1 \%$ cutoff: 27.8 vs. $20.2 \%, p=0.084$; and using a $5 \%$ cut-off: 5.6 vs. $8.7 \%, p=0.244)$. Due to the limited PD-L1-positive cases when using the $5 \%$ cut-off, we decided to use the $1 \%$ cut-off value for the comparison of male with female breast cancer in further analysis. PD-L1 expression on immune cells (Fig. 2) scored as negative or positive showed no significant differences: $38.3 \%$ in male breast cancer and $43.6 \%$ in female breast cancer ( $p=0.299$; Table 2). Looking at the combined positive score (amount of PD-L1-positive cells including tumor cells, lymphocytes or macrophages in relation to the total amount of tumor cells), which is scored as $<1$ or $\geq 1$, it only showed that five female breast cancers and none of the male breast cancers had a score $\geq 1$. For this reason, we did not take this score into account for further analyses.
Table 1 Basic clinicopathologic data for male and female breast cancers $(\mathrm{BC})$

\begin{tabular}{|c|c|c|c|}
\hline Characteristics & Male BC & Female BC & $p$ \\
\hline \multicolumn{3}{|l|}{ Age } & \multirow[t]{3}{*}{$<0.001^{\mathrm{b}}$} \\
\hline Mean, years (SD) & $66.4(11.5)$ & $58.0(13.0)$ & \\
\hline Range & $32-89$ & $33-87$ & \\
\hline \multicolumn{3}{|l|}{ Tumor size } & \multirow[t]{3}{*}{$0.017^{b}$} \\
\hline Mean, cm (SD) & $2.3(1.1)$ & $2.6(1.8)$ & \\
\hline Range & $0.2-7.2$ & $0.2-15.0$ & \\
\hline \multicolumn{3}{|l|}{ Histology ${ }^{a}$} & \multirow[t]{4}{*}{$0.003^{\mathrm{c}}$} \\
\hline Ductal, No. (\%) & $161(97.6)$ & $224(91.4)$ & \\
\hline Lobular, No. (\%) & $3(1.8)$ & $21(8.6)$ & \\
\hline Adenoid cystic, No. (\%) & $1(0.6)$ & - & \\
\hline \multicolumn{3}{|l|}{ Grade } & \multirow[t]{4}{*}{$0.350^{\mathrm{d}}$} \\
\hline 1, No. (\%) & $33(20.1)$ & $41(16.7)$ & \\
\hline 2, No. $(\%)$ & $65(39.6)$ & $88(35.9)$ & \\
\hline 3 , No. $(\%)$ & $66(40.2)$ & $116(47.3)$ & \\
\hline \multicolumn{3}{|l|}{ Lymph node status } & \multirow[t]{3}{*}{$0.742^{\mathrm{d}}$} \\
\hline Negative, No. (\%) & $60(43.5)$ & $109(45.2)$ & \\
\hline Positive, No. (\%) & $78(56.5)$ & $132(54.8)$ & \\
\hline \multicolumn{3}{|l|}{ Molecular subtype } & \multirow[t]{4}{*}{$0.001^{\mathrm{d}}$} \\
\hline Luminal, No. (\%) & $155(94.5)$ & $202(82.1)$ & \\
\hline HER2-driven, No. (\%) & - & $9(3.7)$ & \\
\hline Triple-negative, No (\%) & $9(5.5)$ & $35(14.2)$ & \\
\hline \multicolumn{3}{|l|}{ ER } & \multirow[t]{3}{*}{$\mathbf{0 . 0 0 3}^{\mathrm{d}}$} \\
\hline Negative, No. (\%) & $14(8.6)$ & $48(19.5)$ & \\
\hline Positive, No. (\%) & $149(91.4)$ & $198(80.5)$ & \\
\hline \multicolumn{3}{|l|}{$\mathrm{PR}$} & \multirow[t]{3}{*}{$0.350^{\mathrm{d}}$} \\
\hline Negative, No. (\%) & $52(31.7)$ & $89(36.2)$ & \\
\hline Positive, No. (\%) & $112(68.3)$ & $157(63.8)$ & \\
\hline \multicolumn{3}{|l|}{ HER2 } & \multirow[t]{3}{*}{$0.051^{\mathrm{d}}$} \\
\hline Negative, No. (\%) & $158(96.3)$ & $225(91.5)$ & \\
\hline Positive, No. (\%) & $6(3.7)$ & $21(8.5)$ & \\
\hline
\end{tabular}

Bold indicates significance at $p<0.05$

${ }^{a}$ Ductal includes: Apocrine, Cribriform, Mucinous, Micropapillary, Papillary, Tubular, Medullary and Ductulolobular

${ }^{\mathrm{b}}$ Independent samples $t$-test

${ }^{\mathrm{c}}$ Fisher's exact test

${ }^{\mathrm{d}}$ Pearson chi-square test

The comparison between expression of PD-L1 on tumor cells and immune cells is shown in Table 3. In male breast cancer, PD-L1 expression in tumor and immune cells was concordant in $71 \%(115 / 162)$ of the patients, while in $15 /$ $162(9.3 \%)$, PD-L1 was positive on tumor cells but negative on immune cells. In addition, in 32/162 (19.2\%), PD-L1 was negative on the tumor cells, while immune cells were positive $(p<0.001)$. In female breast cancer, PD-L1 expression in tumor and immune cells was concordant in $66.4 \%(145 / 218)$ of the patients, while in 11/218 (5.0\%), PD-L1 was positive on tumor cells but negative on immune cells. Lastly, in 62/218 (28.4\%), PD-L1 was negative on the tumor cells, while immune cells were positive $(p<0.001)$. 
Fig. 1 Immunohistochemical staining for PD-1 in male breast cancer. a Tumor negative for PD1.b Tumor with tumor-infiltrating lymphocytes positive for PD-1 (some as illustration marked by red boxes)

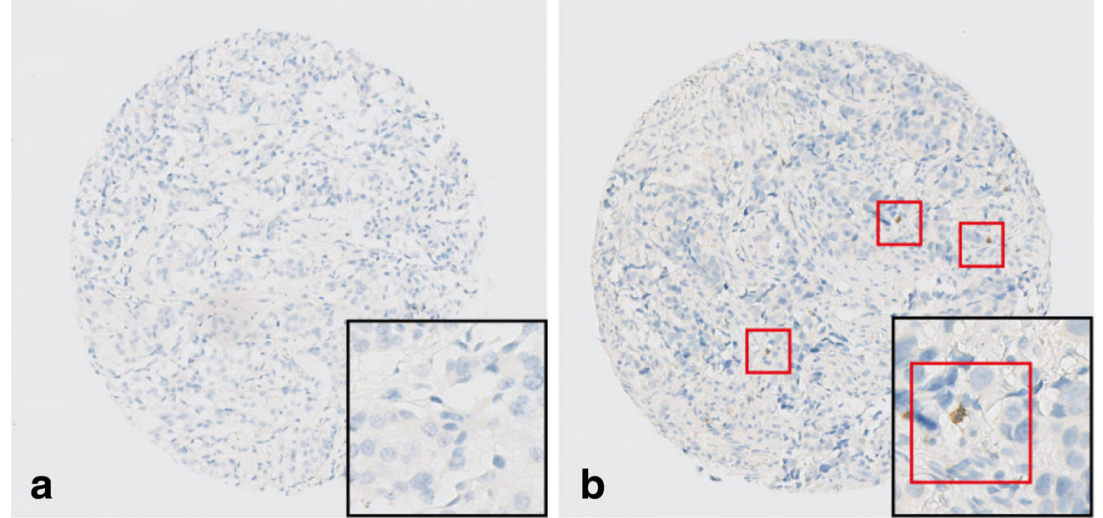

In a subgroup analysis, PD-1 was significantly more often positive in grade 3 tumors, in both male and female breast cancer. In men, PD-1 expression was also significantly correlated with larger tumors $(>2.0 \mathrm{~cm})$ and positive lymph node status, while in female breast cancer, PD-1 expression was also correlated with ER-negative tumors, HER2-positive tumors, and more aggressive molecular subtypes (because of small subgroups, we compared luminal subtype to a combined group with HER2-driven and TNBC) (Table 4).

Concerning PD-L1 expression on tumor cells in male breast cancer, we only found a correlation between PD-L1 and grade 3 tumors. In women, we did not observe a correlation with tumor grade, but did observe associations of PD-L1 with ER and PR negativity and a more aggressive surrogate molecular subtype (Table 5). In regard to PD-L1 expression on immune cells, we did not find correlations with any of the selected clinicopathological variables in male breast cancer. In female breast cancer, similar to tumor PD-L1 expression, the immune cell PD-L1 expression was associated with ER and PR negativity and a more aggressive surrogate molecular subtype (Table 5). Furthermore, immune cell PD-L1 positivity was more often observed in grade 3 tumors compared to lower grade tumors.

\subsection{Survival Analysis}

Sufficient survival data were available for 110 male and 218 female breast cancer patients. Median follow-up time for male breast cancer patients was 4.3 years (range $0.0-20.3$ years) and for female breast cancer patients it was 8.5 years (range $0.1-$ 22.1 years). PD-1 and PD-L1 expression on tumor and immune cells did not correlate significantly with OS in either male or female breast cancer patients (Fig. 3). Also, in a multivariate analysis (including age, tumor size $(\leq 2.0 \mathrm{~cm}$ or $>2.0 \mathrm{~cm})$, tumor grade ( 3 vs. 1 or 2 ) and lymph node status), PD-1 and PDL1 expression, both on tumor and immune cells, showed no prognostic value for OS in male and female breast cancer.

Since we observed correlations of PD-1 and PD-L1 with some of the selected clinicopathological variables in the subgroup analysis, we also evaluated if combinations of these variables with PD-1 or PD-L1 showed prognostic values. In men, this was not the case, while in women, the combination of PD-L1 on tumor cells with tumor grade and PD-L1 on immune cells with ER status showed prognostic values, both in a univariate $(p=0.029$ and $p=0.007)$ and multivariate analysis (including age, tumor size $(\leq 2.0 \mathrm{~cm}$ or $>$ $2.0 \mathrm{~cm}$ ), tumor grade ( 3 vs. 1 or 2 ) and lymph node status), $p=0.021$ and $p=0.012$ (Fig. 4). Patients with grade 3 tumors that were tumor PD-L1-negative showed a tendency to have the worst OS, while patients with grade 3/tumor PDL1-positive tumors seemed to have similar survival as patients with low grade tumors (10-year OS 54 vs. $77 \%, p=$ 0.063). Additionally, patients with ER-negative tumors that were immune cell PD-L1-negative had a significantly worse OS compared to patients with ER-negative but PD-L1positive tumors (10-year OS 46 vs. $69 \%, p=0.015$ ).
Fig. 2 Immunohistochemical staining for PD-L1 in male breast cancer. a Tumor negative for PDL1. b Tumor with PD-L1-positive tumor cells. c Tumor with PD-L1positive immune cells
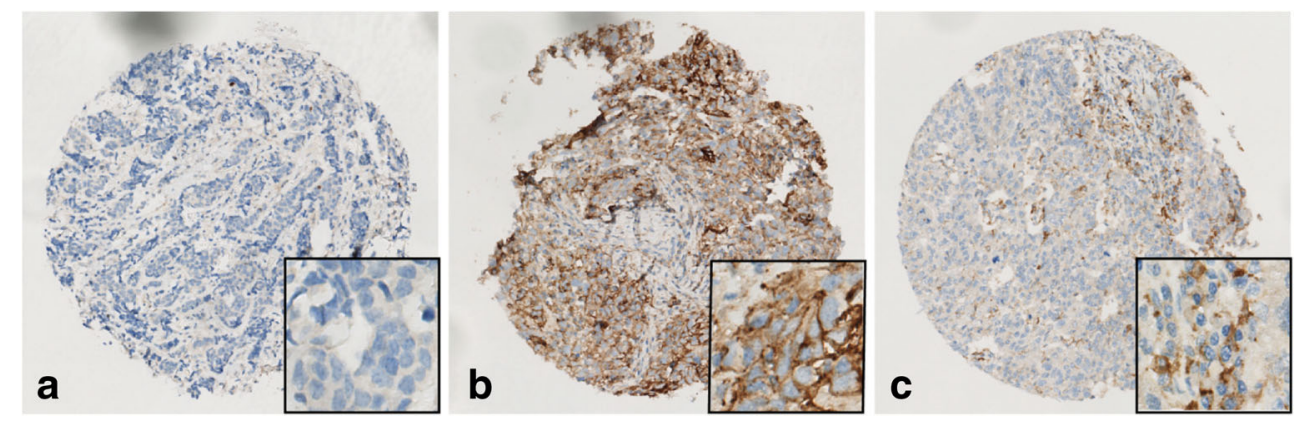
Table 2 PD-1 and PD-L1 expression in male and female breast cancer (BC)

\begin{tabular}{|c|c|c|c|}
\hline Characteristics & Male BC & Female BC & $p$ \\
\hline PD-1 & & & 0.002 \\
\hline Negative, No. (\%) & $72(51.1)$ & $83(34.7)$ & \\
\hline Positive, No. (\%) & 69 (48.9) & $156(65.3)$ & \\
\hline $\begin{array}{l}\text { PD-L1 on tumor cells } \\
1 \% \text { cut-off }\end{array}$ & & & 0.084 \\
\hline Negative, No. (\%) & $117(72.2)$ & $174(79.8)$ & \\
\hline Positive, No. (\%) & $45(27.8)$ & $44(20.2)$ & \\
\hline $\begin{array}{l}\text { PD-L1 on tumor cells } \\
5 \% \text { cut-off }\end{array}$ & & & 0.244 \\
\hline Negative, No. (\%) & $153(94.4)$ & $199(91.3)$ & \\
\hline Positive, No. (\%) & $9(5.6)$ & $19(8.7)$ & \\
\hline PD-L1 on immune cells & & & 0.299 \\
\hline Negative, No. $(\%)$ & $100(61.7)$ & $123(56.4)$ & \\
\hline Positive, No. (\%) & $62(38.3)$ & 95 (43.6) & \\
\hline
\end{tabular}

Bold indicates significance at $p<0.05$; Pearson Chi-square test

\section{Discussion}

The aim of this study was to evaluate PD-1 and PD-L1 expression in male breast cancer, compare their expression frequency to that of female breast cancer, and compare prognostic values in both populations.

We demonstrated a significantly lower frequency of PD-1 expression in male breast cancer compared to female breast cancer. In the literature, PD-1 expression has been associated with ER and PR negativity [10,13,26], and with TNBC [13, 27]. In this study, almost $94 \%$ of the male tumors were of the luminal subtype, while in the female group around $83 \%$ of the tumors were luminal, which is concordant with the literature $[28,29]$. Additionally, male breast cancers may have fewer TILs, according to the finding by Loi et al. stating that luminal breast cancers have fewer tumor-infiltrating lymphocytes (TILs) in comparison with triple-negative and HER2positive breast cancers [30]. In addition to this finding, a low amount of TILs in male breast cancer has already been reported at a conference [31]. Together, this might explain the lower PD-1 expression level we found in tumors of men with breast cancer compared to women. Furthermore, PD-1 expression in both genders was associated with a higher tumor grade and, in men, this was associated with a larger tumor size. This finding conforms to previously published data $[10,13,26]$.

For PD-L1 expression, no significant gender-specific difference was observed. In the subgroup analysis for male breast cancer, we have only found a correlation between PD-L1 on tumor cells and grade 3 tumors. In female breast cancer, we observed that PD-L1 expression in tumor and immune cells was associated with ER/PR negativity and a worse surrogate molecular subtype. Additionally, PD-L1 on immune cells was also correlated to grade 3 tumors. These associations are in agreement with the literature, since several previous studies have also described correlations between PD-L1 and unfavorable clinicopathological variables, including larger tumor size, higher grade, ER- and PR-negative tumors, aggressive molecular subtype, positive lymph nodes, and lymphovascular invasion [7-9, 11, 12, 27, 32-34].

In the overall survival analysis, no significant prognostic value was observed for PD-1 and PD-L1 on tumor and immune cells in either male and female breast cancer. In the published literature, the prognostic value of PD-1 and PD-L1 in female breast cancer is equivocal, since previous studies have described different outcomes. In two studies, PD-1 was associated with worse OS and/or DFS [10,13], but only one persisted significantly after correcting for covariates in multivariate analysis [10]. For PD-L1, some studies described a correlation between expression and worse survival $[8,11]$, while others observed better survival in PD-L1expressing tumors [7]. In addition, other studies have demonstrated better survival in tumor and immune PD-L1-positive cancers [34], while two other studies did not find a correlation between PD-L1 and survival $[33,35]$ as we did. Furthermore, some studies only reported an association between PD-L1 and survival for the basal subtype, again with contradictory results $[9,12]$.

In the subgroup analysis, we observed significant prognostic values for tumor PD-L1 combined with tumor grade (grade $3 \mathrm{vs,}$ 1 or 2) and immune PD-L1 combined with ER status in female breast cancer. In the corresponding survival curves, we noticed a tendency for patients with grade 3/PD-L1-negative tumors to have worse OS than patients with grade 3/tumor PD-L1-positive, or lower grade tumors. Additionally, patients with ER-negative/ immune PD-L1-negative tumors had a significantly worse OS compared to ER-negative/immune PD-L1-positive, or ERpositive patients. Although correlations with PD-L1 and higher
Table 3 PD-L1 expression in tumor and immune cells in male and female breast cancer (BC)

\begin{tabular}{|c|c|c|c|c|c|c|}
\hline & \multicolumn{2}{|l|}{ Male BC } & & \multicolumn{2}{|l|}{ Female BC } & \multirow[t]{3}{*}{$p$} \\
\hline & \multicolumn{5}{|c|}{ PD-L1 on tumor cells } & \\
\hline & Negative & Positive & $p$ & Negative & Positive & \\
\hline \multirow{2}{*}{$\begin{array}{l}\text { PD-L1 on immune cells } \\
\text { Negative, No. }(\%)\end{array}$} & & & $<0.001$ & & & $<0.001$ \\
\hline & $85(52.5)$ & $15(9.3)$ & & $112(51.4)$ & $11(5.0)$ & \\
\hline Positive, No. (\%) & $32(19.2)$ & $30(18.5)$ & & $62(28.4)$ & $33(15.0)$ & \\
\hline
\end{tabular}

Bold indicates significance at $p<0.05$; Pearson Chi-square test 
Table 4 Association of PD-1 expression with selected clinicopathological variables in male and female breast cancer (BC)

\begin{tabular}{|c|c|c|c|c|}
\hline & & $\begin{array}{l}\text { PD-1 negative } \\
\text { No. }(\%)\end{array}$ & $\begin{array}{l}\text { PD-1 positive } \\
\text { No. }(\%)\end{array}$ & $p$ \\
\hline \multirow[t]{19}{*}{ Male BC } & Size $^{\mathrm{a}}$ & & & $0.014^{\mathrm{b}}$ \\
\hline & $\leq 2.0 \mathrm{~cm}$ & $43(62.3)$ & $26(37.7)$ & \\
\hline & $>2.0 \mathrm{~cm}$ & $29(41.1)$ & $41(58.6)$ & \\
\hline & Grade & & & $0.042^{\mathrm{b}}$ \\
\hline & 1 & $20(64.5)$ & $11(35.5)$ & \\
\hline & 2 & $28(57.1)$ & $21(42.9)$ & \\
\hline & 3 & $24(39.3)$ & $37(60.7)$ & \\
\hline & Molecular subtype & & & $0.741^{\mathrm{c}}$ \\
\hline & Luminal & $68(51.5)$ & $64(48.5)$ & \\
\hline & HER2-driven/TNBC & $4(44.4)$ & $5(55.6)$ & \\
\hline & ER & & & $0.959^{\mathrm{b}}$ \\
\hline & Negative & $6(50.0)$ & $6(50.0)$ & \\
\hline & Positive & $65(50.8)$ & $63(49.2)$ & \\
\hline & PR & & & $0.148^{\mathrm{b}}$ \\
\hline & Negative & $18(41.9)$ & $25(58.1)$ & \\
\hline & Positive & $54(55.1)$ & $44(44.9)$ & \\
\hline & HER2 & & & $0.111^{\mathrm{c}}$ \\
\hline & Negative & $71(52.6)$ & $64(47.4)$ & \\
\hline & Positive & $1(16.7)$ & $5(83.3)$ & \\
\hline \multirow[t]{19}{*}{ Female BC } & Size $^{\mathrm{a}}$ & & & $0.628^{\mathrm{b}}$ \\
\hline & $\leq 2.0 \mathrm{~cm}$ & $41(36.6)$ & $71(63.4)$ & \\
\hline & $>2.0 \mathrm{~cm}$ & $42(33.6)$ & $83(66.4)$ & \\
\hline & Grade & & & $0.032^{\mathrm{b}}$ \\
\hline & 1 & $16(39.0)$ & $25(61.0)$ & \\
\hline & 2 & $37(44.0)$ & $47(56.0)$ & \\
\hline & 3 & $30(26.5)$ & $83(73.5)$ & \\
\hline & Molecular subtype & & & $0.046^{\mathrm{b}}$ \\
\hline & Luminal & $74(37.6)$ & $123(62.4)$ & \\
\hline & HER2-driven/TNBC & $9(21.4)$ & $33(78.6)$ & \\
\hline & ER & & & $0.016^{\mathrm{b}}$ \\
\hline & Negative & $9(19.6)$ & $37(80.4)$ & \\
\hline & Positive & $74(38.3)$ & $119(61.7)$ & \\
\hline & PR & & & $0.475^{\mathrm{b}}$ \\
\hline & Negative & $27(31.8)$ & $58(68.2)$ & \\
\hline & Positive & $56(36.4)$ & $98(63.6)$ & \\
\hline & HER2 & & & $0.015^{\mathrm{b}}$ \\
\hline & Negative & $81(37.0)$ & $138(63.0)$ & \\
\hline & Positive & $2(10.0)$ & $18(90.0)$ & \\
\hline
\end{tabular}

Bold indicates significance at $p<0.05$

${ }^{\text {a }}$ Cut-off is based on T-stage

${ }^{\mathrm{b}}$ Pearson chi-square test

${ }^{\mathrm{c}}$ Fisher's exact test tumor grade and ER negativity have been described before [7-9, $11,12,26,32-34]$, as far as we know, no earlier studies have combined receptor status with the survival analysis.

Comparison of the literature on PD-1 and PD-L1 expression remains difficult since there are many different antibodies in use, which were unfortunately not always properly validated. This has led to a wide variation of expression values, ranging from 15.8 to 91.3\% for PD-1 [10, 13, 26, 27] and from 1.7 to $66 \%$ for PD-L1 $[7-9,11,21,26,27,32-35]$. At the same time, there is no standardized method for scoring. A variety of cut-off values have been 
Table 5 Association of tumor and immune cell PD-L1 expression with selected clinicopathological variables in male and female breast cancer (BC)

\begin{tabular}{|c|c|c|c|c|c|c|c|}
\hline & & $\begin{array}{l}\text { Tumor PD-L1 } \\
\text { negative } \\
\text { No. }(\%)\end{array}$ & $\begin{array}{l}\text { Tumor PD-L1 } \\
\text { positive } \\
\text { No. }(\%)\end{array}$ & $p$ & $\begin{array}{l}\text { Immune PD-L1 } \\
\text { negative } \\
\text { No. }(\%)\end{array}$ & $\begin{array}{l}\text { Immune PD-L1 } \\
\text { positive } \\
\text { No. }(\%)\end{array}$ & $p$ \\
\hline \multirow[t]{19}{*}{ Male BC } & $\operatorname{Size}^{\mathrm{a}}$ & & & $0.532^{\mathrm{b}}$ & & & $0.716^{\mathrm{b}}$ \\
\hline & $\leq 2.0 \mathrm{~cm}$ & $59(75.6)$ & $19(24.4)$ & & $49(62.8)$ & $29(37.2)$ & \\
\hline & $>2.0 \mathrm{~cm}$ & $57(71.3)$ & $23(28.7)$ & & $48(60.0)$ & $32(40.0)$ & \\
\hline & Grade & & & $0.032^{\mathrm{b}}$ & & & $0.820^{\mathrm{b}}$ \\
\hline & 1 & $25(78.1)$ & 7 (21.9) & & $21(65.6)$ & $11(34.4)$ & \\
\hline & 2 & $52(81.3)$ & $12(18.8)$ & & $38(59.4)$ & $26(40.6)$ & \\
\hline & 3 & $40(61.5)$ & $25(38.5)$ & & $41(63.1)$ & $24(36.9)$ & \\
\hline & Molecular subtype & & & $0.706^{\mathrm{c}}$ & & & $0.731^{\mathrm{c}}$ \\
\hline & Luminal & $111(73.0)$ & $41(27.0)$ & & $95(62.5)$ & $57(37.5)$ & \\
\hline & HER2-driven/TNBC & $6(66.7)$ & $3(33.3)$ & & $5(55.6)$ & $4(44.4)$ & \\
\hline & ER & & & $0.759^{\mathrm{c}}$ & & & $0.441^{\mathrm{b}}$ \\
\hline & Negative & $11(78.6)$ & $3(21.4)$ & & $10(71.4)$ & $4(28.6)$ & \\
\hline & Positive & $105(71.9)$ & $41(28.1)$ & & $89(61.0)$ & $57(39.0)$ & \\
\hline & PR & & & $0.686^{\mathrm{b}}$ & & & $0.199^{\mathrm{b}}$ \\
\hline & Negative & $36(70.6)$ & $15(29.4)$ & & $28(54.9)$ & $23(45.1)$ & \\
\hline & Positive & $81(73.6)$ & $29(26.4)$ & & $72(65.5)$ & $38(34.5)$ & \\
\hline & HER2 & & & $0.347^{\mathrm{c}}$ & & & $0.674^{\mathrm{c}}$ \\
\hline & Negative & $114(73.5)$ & $41(26.5)$ & & $97(62.6)$ & $58(37.4)$ & \\
\hline & Positive & $3(50.0)$ & $3(50.0)$ & & $3(50.0)$ & $3(50.0)$ & \\
\hline \multirow[t]{19}{*}{ Female BC } & Size $^{\mathrm{a}}$ & & & $0.605^{\mathrm{b}}$ & & & $0.742^{\mathrm{b}}$ \\
\hline & $\leq 2.0 \mathrm{~cm}$ & $80(81.6)$ & $18(18.4)$ & & $57(58.2)$ & $41(41.8)$ & \\
\hline & $>2.0 \mathrm{~cm}$ & $93(78.8)$ & $25(21.2)$ & & $66(55.9)$ & $52(44.1)$ & \\
\hline & Grade & & & $0.210^{\mathrm{b}}$ & & & $0.011^{b}$ \\
\hline & 1 & $30(85.7)$ & $5(14.3)$ & & $23(65.7)$ & $12(34.3)$ & \\
\hline & 2 & $63(84.0)$ & $12(16.0)$ & & $50(66.7)$ & $25(33.3)$ & \\
\hline & 3 & $81(75.0)$ & $27(25.0)$ & & $50(46.3)$ & $58(53.7)$ & \\
\hline & Molecular subtype & & & $<0.001^{\mathrm{b}}$ & & & $0.001^{b}$ \\
\hline & Luminal & $152(84.9)$ & $27(15.1)$ & & $110(61.5)$ & $69(38.5)$ & \\
\hline & HER2-driven/TNBC & $22(56.4)$ & $17(43.6)$ & & $13(33.3)$ & $26(66.7)$ & \\
\hline & ER & & & $<0.001^{\text {b }}$ & & & $<0.001^{\text {b }}$ \\
\hline & Negative & $24(55.8)$ & $19(44.2)$ & & $14(32.6)$ & $29(67.4)$ & \\
\hline & Positive & $150(85.7)$ & $25(14.3)$ & & $109(62.3)$ & $66(37.7)$ & \\
\hline & PR & & & $0.006^{\mathrm{b}}$ & & & $0.010^{b}$ \\
\hline & Negative & $56(70.0)$ & $24(30.0)$ & & $36(45.0)$ & $44(55.0)$ & \\
\hline & Positive & $118(85.5)$ & $20(14.5)$ & & $87(63.0)$ & $51(37.0)$ & \\
\hline & HER2 & & & $0.138^{\mathrm{c}}$ & & & $0.893^{\mathrm{b}}$ \\
\hline & Negative & $161(81.3)$ & 37 (18.7) & & $112(56.6)$ & $86(43.4)$ & \\
\hline & Positive & $13(65.0)$ & $7(35.0)$ & & $11(55.0)$ & $9(45.0)$ & \\
\hline
\end{tabular}

Bold indicates significance at $p<0.05$

${ }^{\text {a }}$ Cut-off is based on T-stage

${ }^{\mathrm{b}}$ Pearson chi-square test

${ }^{\mathrm{c}}$ Fisher's exact test

used in literature from 1 to $50 \%$, leading to different percentages of positive cases [36]. This is something we have also observed in our cohort for PD-L1, comparing a $1 \%$ cut-off to a $5 \%$ cut-off. In addition, PD-L1 is expressed both on tumor cells and immune cells, and while most studies only scored expression on tumor cells, some also reported the percentage of PD-L1-positive immune cells as we did $[33,34,36]$. This indicates that further standardization in laboratory and scoring methods is important. 
a

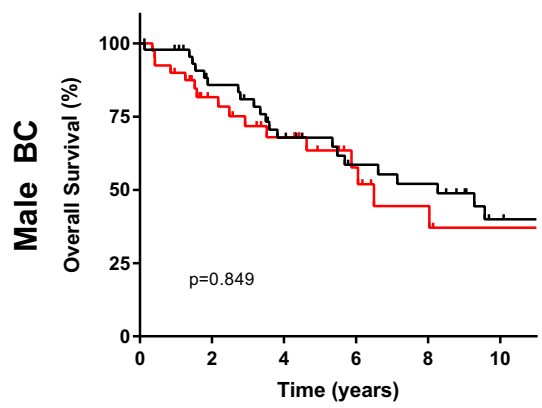

d

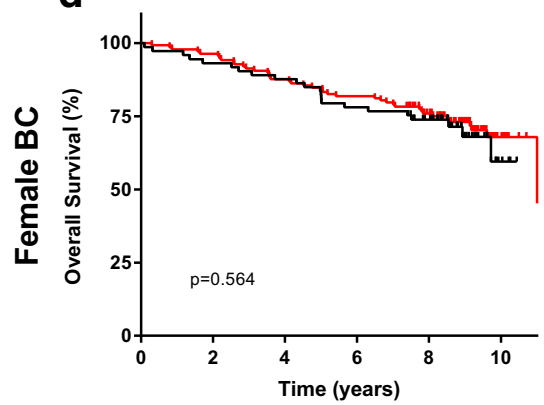

b

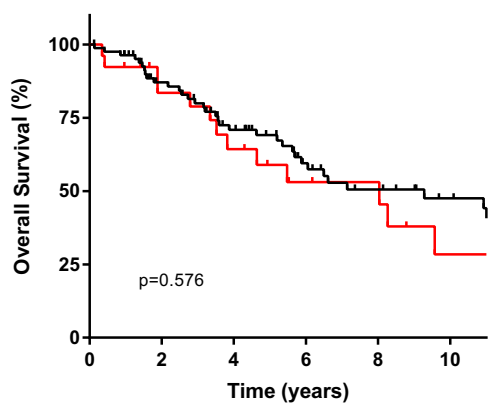

e

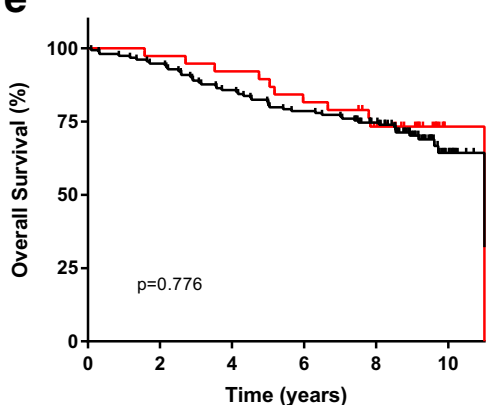

PD-L1 immune cells

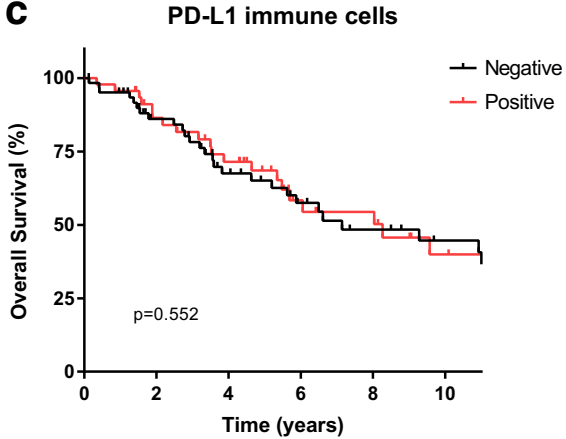

f

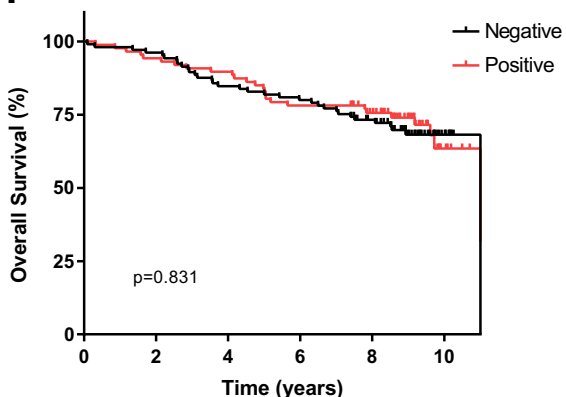

Fig. 3 Kaplan-Meier curves for overall survival for PD-1 (a, d), PD-L1 in tumor cells (b, e) and PD-L1 in immune cells (c, f) in male and female breast cancer (BC) patients

To evaluate PD-1 and PD-L1 expression, we used TMAs. This may be a limitation since PD-1 and PD-L1 expression is thought to be heterogeneous. This is the rationale for why we took three cores per FFPE donor block representing different tumor areas. We compared PD-L1 expression in tumors of ten patients on TMA and whole slides and noticed that, in half of the cases, these were in complete agreement, while for the other half, only minimal differences were found. This indicates that our TMAs were sufficiently representative. Furthermore, due to the scarcity of male breast cancer, we had a relatively small cohort of male patients, providing limitations for subgroup analyses.

To conclude, PD-1 expression is less often positive in male breast cancer compared to female breast cancer, while PD-L1 expression is comparable between the two groups. Although PD-1 and PD-L1 are not definite indicators for good or bad responses, male breast cancer patients may respond differently to checkpoint immunotherapy with PD-1 inhibitors than female

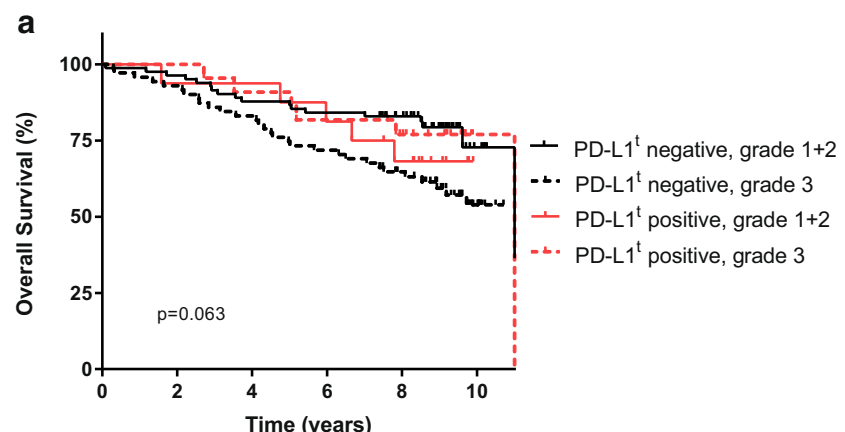

patients. Additionally, we observed that both female breast cancer patients with grade 3 tumors and lack of tumor PD-L1 expression and patients with ER-negative/immune PD-L1-negative breast tumors have a worse overall survival outcome compared to the PD-L1-positive patients.

Acknowledgements We would like to thank Ms. S. Raman for critically reading our manuscript, and the tissue facility of the UMCU for their help with the immunohistochemical stainings.

\section{Compliance with Ethical Standards}

Funding Quirine F. Manson is financially supported by the Dutch Cancer Society, under Grant KUN2014-7032.

Conflict of Interest Quirine F. Manson, Natalie D. ter Hoeve, Horst Buerger, Cathy B. Moelans, and Paul J. van Diest, declare that they have no conflicts of interest that might be relevant to the contents of this manuscript.

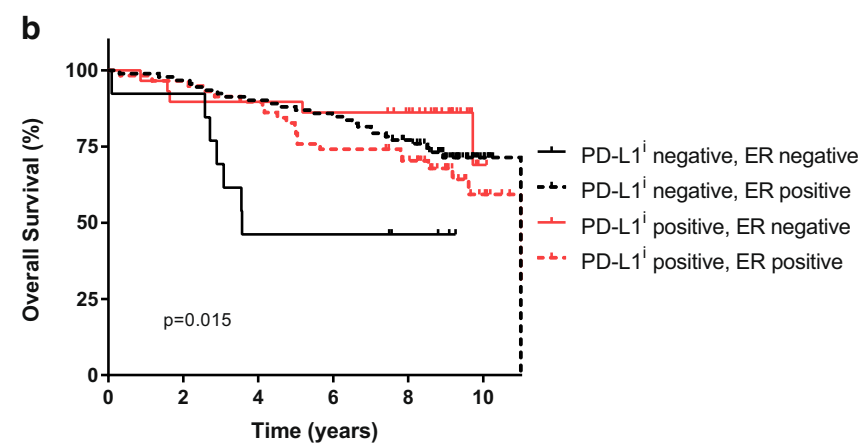

Fig. 4 Kaplan-Meier curves for overall survival in female breast cancer patients for a PD-L1 in tumor cells in combination with tumor grade (grade 3 vs. 1 or 2), and $\mathbf{b}$ PD-L1 in immune cells combined with ER status 
Open Access This article is distributed under the terms of the Creative Commons Attribution-NonCommercial 4.0 International License (http:// creativecommons.org/licenses/by-nc/4.0/), which permits any noncommercial use, distribution, and reproduction in any medium, provided you give appropriate credit to the original author(s) and the source, provide a link to the Creative Commons license, and indicate if changes were made.

\section{References}

1. Anderson WF, Jatoi I, Tse J, Rosenberg PS. Male breast cancer: a population-based comparison with female breast cancer. J Clin Oncol. 2010;28(2):232-9.

2. Kornegoor R, van Diest PJ, Buerger H, Korsching E. Tracing differences between male and female breast cancer: both diseases own a different biology. Histopathology. 2015;67(6):888-97.

3. Kornegoor R, Verschuur-Maes AH, Buerger H, Hogenes MC, de Bruin PC, Oudejans JJ, et al. Immunophenotyping of male breast cancer. Histopathology. 2012;61(6):1145-55.

4. Kornegoor R, Verschuur-Maes AH, Buerger H, Hogenes MC, de Bruin PC, Oudejans JJ, et al. Molecular subtyping of male breast cancer by immunohistochemistry. Mod Pathol. 2012;25(3):398-404.

5. Leone JP, Zwenger AO, Iturbe J, Leone J, Leone BA, Vallejo CT, et al. Prognostic factors in male breast cancer: a population-based study. Breast Cancer Res Treat. 2016;156(3):539-48.

6. Liu N, Johnson KJ, Ma CX. Male breast cancer: an updated surveillance, epidemiology, and end results data analysis. Clin Breast Cancer. 2018;18(5):e997-1002.

7. Baptista MZ, Sarian LO, Derchain SF, Pinto GA, Vassallo J. Prognostic significance of PD-L1 and PD-L2 in breast cancer. Hum Pathol. 2016;47(1):78-84.

8. Li Z, Dong P, Ren M, Song Y, Qian X, Yang Y, et al. PD-L1 expression is associated with tumor FOXP3(+) regulatory T-cell infiltration of breast Cancer and poor prognosis of patient. J Cancer. 2016;7(7):784-93.

9. Muenst S, Schaerli AR, Gao F, Daster S, Trella E, Droeser RA, et al. Expression of programmed death ligand 1 (PD-L1) is associated with poor prognosis in human breast cancer. Breast Cancer Res Treat. 2014;146(1):15-24.

10. Muenst S, Soysal SD, Gao F, Obermann EC, Oertli D, Gillanders WE. The presence of programmed death 1 (PD-1)-positive tumorinfiltrating lymphocytes is associated with poor prognosis in human breast cancer. Breast Cancer Res Treat. 2013;139(3):667-76.

11. Qin T, Zeng YD, Qin G, Xu F, Lu JB, Fang WF, et al. High PD-L1 expression was associated with poor prognosis in 870 Chinese patients with breast cancer. Oncotarget. 2015;6(32):33972-81.

12. Sabatier R, Finetti P, Mamessier E, Adelaide J, Chaffanet M, Ali HR, et al. Prognostic and predictive value of PDL1 expression in breast cancer. Oncotarget. 2015;6(7):5449-64.

13. Sun S, Fei X, Mao Y, Wang X, Garfield DH, Huang O, et al. PD-1(+ ) immune cell infiltration inversely correlates with survival of operable breast cancer patients. Cancer Immunol Immunother. 2014;63(4):395-406.

14. Konishi J, Yamazaki K, Azuma M, Kinoshita I, Dosaka-Akita H, Nishimura M. B7-H1 expression on non-small cell lung cancer cells and its relationship with tumor-infiltrating lymphocytes and their PD-1 expression. Clin Cancer Res. 2004;10(15):5094-100.

15. Hino R, Kabashima K, Kato Y, Yagi H, Nakamura M, Honjo T, et al. Tumor cell expression of programmed cell death-1 ligand 1 is a prognostic factor for malignant melanoma. Cancer. 2010;116(7):1757-66.

16. Thompson RH, Dong H, Lohse CM, Leibovich BC, Blute ML, Cheville JC, et al. PD-1 is expressed by tumor-infiltrating immune cells and is associated with poor outcome for patients with renal cell carcinoma. Clin Cancer Res. 2007;13(6):1757-61.

17. Thompson RH, Gillett MD, Cheville JC, Lohse CM, Dong H, Webster WS, et al. Costimulatory B7-H1 in renal cell carcinoma patients: Indicator of tumor aggressiveness and potential therapeutic target. Proc Natl Acad Sci U S A. 2004;101(49):17174-9.

18. Huang Y, Zhang SD, McCrudden C, Chan KW, Lin Y, Kwok HF. The prognostic significance of PD-L1 in bladder cancer. Oncol Rep. 2015;33(6):3075-84.

19. Hamanishi J, Mandai M, Iwasaki M, Okazaki T, Tanaka Y, Yamaguchi K, et al. Programmed cell death 1 ligand 1 and tumorinfiltrating CD8+ $\mathrm{T}$ lymphocytes are prognostic factors of human ovarian cancer. Proc Natl Acad Sci U S A. 2007;104(9):3360-5.

20. Chawla A, Philips AV, Alatrash G, Mittendorf E. Immune checkpoints: a therapeutic target in triple negative breast cancer. Oncoimmunology. 2014;3(3):e28325.

21. Mittendorf EA, Philips AV, Meric-Bernstam F, Qiao N, Wu Y, Harrington S, et al. PD-L1 expression in triple-negative breast cancer. Cancer Immunol Res. 2014;2(4):361-70.

22. Wein L, Luen SJ, Savas P, Salgado R, Loi S. Checkpoint blockade in the treatment of breast cancer: current status and future directions. Br J Cancer. 2018;119(1):4-11.

23. Elston CW, Ellis IO. Pathological prognostic factors in breast cancer. I. the value of histological grade in breast cancer: experience from a large study with long-term follow-up. Histopathology. 2002;41(3A):154-61.

24. van Diest PJ. No consent should be needed for using leftover body material for scientific purposes. BMJ. 2002;325(7365):648-51.

25. Vermeulen JF, van Brussel AS, van der Groep P, Morsink FH, Bult $\mathrm{P}$, van der Wall E, et al. Immunophenotyping invasive breast cancer: paving the road for molecular imaging. BMC Cancer. 2012;12:240.

26. Ghebeh H, Barhoush E, Tulbah A, Elkum N, Al-Tweigeri T, Dermime S. FOXP3+ Tregs and B7-H1+/PD-1+ T lymphocytes co-infiltrate the tumor tissues of high-risk breast cancer patients: implication for immunotherapy. BMC Cancer. 2008;8:57.

27. Gatalica Z, Snyder C, Maney T, Ghazalpour A, Holterman DA, Xiao $\mathrm{N}$, et al. Programmed cell death 1 (PD-1) and its ligand (PD-L1) in common cancers and their correlation with molecular cancer type. Cancer Epidemiol Biomark Prev. 2014;23(12):2965-70.

28. Cardoso F, Bartlett JMS, Slaets L, van Deurzen CHM, van LeeuwenStok E, Porter P, et al. Characterization of male breast cancer: results of the EORTC 10085/TBCRC/BIG/NABCG international male breast Cancer program. Ann Oncol. 2018;29(2):405-17.

29. Fentiman IS. The biology of male breast cancer. Breast. 2018;38:132-5.

30. Loi S. Tumor-infiltrating lymphocytes, breast cancer subtypes and therapeutic efficacy. Oncoimmunology. 2013;2(7):e24720.

31. Abdeljaoued S, Bettaieb I, Adouni O, Goucha A, Ghozzi R, Bouzaiene $\mathrm{H}$, et al. Prognostic significance of CD8+tumor-infiltrating lymphocytes (TILs), CD4+TILs and TILs in male breast cancer. Cancer Res. 2017;77(4 supplement):P3-15-01.

32. Ghebeh H, Mohammed S, Al-Omair A, Qattan A, Lehe C, AlQudaihi G, et al. The B7-H1 (PD-L1) T lymphocyte-inhibitory molecule is expressed in breast cancer patients with infiltrating ductal carcinoma: correlation with important high-risk prognostic factors. Neoplasia. 2006;8(3):190-8.

33. Guo L, Li WB, Zhu XX, Ling Y, Qiu T, Dong L, et al. PD-L1 expression and CD274 gene alteration in triple-negative breast cancer: implication for prognostic biomarker. Springerplus. 2016;5:805.

34. Arias-Pulido H, Cimino-Mathews A, Chaher N, Qualls C, Joste N, Colpaert $\mathrm{C}$, et al. The combined presence of $\mathrm{CD} 20+\mathrm{B}$ cells and PD-L1 + tumor-infiltrating lymphocytes in inflammatory breast cancer is prognostic of improved patient outcome. Breast Cancer Res Treat. 2018;171(2):273-82.

35. Ali HR, Glont SE, Blows FM, Provenzano E, Dawson SJ, Liu B, et al. PD-L1 protein expression in breast cancer is rare, enriched in basal-like tumours and associated with infiltrating lymphocytes. Ann Oncol. 2015;26(7):1488-93.

36. Sun WY, Lee YK, Koo JS. Expression of PD-L1 in triple-negative breast cancer based on different immunohistochemical antibodies. J Transl Med. 2016;14(1):173. 